Energy Research Journal 1 (2): 78-81, 2010

ISSN 1949-0151

(C) 2010 Science Publications

\title{
Fabrication of Composite Material from Sea Mussel Shells and White Clay as a Versatile Sorbent
}

\author{
${ }^{1}$ Singto Sakulkhaemaruethai, ${ }^{1}$ Churairat Duangduen, ${ }^{2}$ Weraporn Pivsa-Art and ${ }^{3}$ Sommai Pivsa-Art \\ ${ }^{1}$ Department of Chemistry, Faculty of Science and Technology, \\ ${ }^{2}$ Department of Chemical and Material Engineering, Faculty of Engineering, \\ ${ }^{3}$ Department of Material and Metallurgical Engineering, Faculty of Engineering, \\ Rajamangala University of Technology Thanyaburi, Klong 6, Thanyaburi Pathumthani, Thailand 12110
}

\begin{abstract}
Problem statement: The removal of heavy metals contaminated in aqueous solution/wastewater has been causing worldwide concern. However, the adsorbent materials are usually limited due to their high cost and environmentally benign. To overcome the above-mentioned disadvantages, low-cost and effective adsorbents are in demand. Approach: In this study, the sea mussel shells/natural clay beads were prepared for using as low-cost sorbent to remove $\mathrm{Cd}$ in the synthetic wastewater. Results: The sorbent were characterized using Scanning Electron Microscopy (SEM). The adsorption of $\mathrm{Cd}(\mathrm{II})$ ions from aqueous solution onto adsorbent has been investigated using kinetic approach to evaluate the effect of initial concentration and contact time on the removal of Cd. In adsorption studies, residual Cd(II) ion concentration reached equilibrium in duration of $240 \mathrm{~min}$ for initial $\mathrm{Cd}$ concentration of $5 \mathrm{ppm}$. The maximum removal achieves $99.75 \mathrm{mg} \mathrm{g}^{-1}$. Conclusion/Recommendations: The present results suggest that the adsorbent derived from sea mussel shells/natural clay bead is expected to be an economical material for removal of $\mathrm{Cd}(\mathrm{II})$ ions effectively from contaminated water.
\end{abstract}

Key words: White clay, composite material, sea mussel, sorbent, adsorption

\section{INTRODUCTION}

The progressive increase of industrial technology results in continuous increase of heavy metals such as $\mathrm{Hg}, \mathrm{Pb}, \mathrm{Cr}, \mathrm{Ni}, \mathrm{Cu}, \mathrm{Cd}$ and $\mathrm{Zn}$ in the aquatic environment, so that a great effort has been devoted for minimizing these harzadous pollutants. A variety of methods have been proposed for the treatment of wastewater such as chemical precipitation (Matlock et al., 2001), electrochemical reduction, ion exchange (Inglezakis et al., 2007), membrane separation (Aravindan et al., 2009) and adsorption (Gupta and Sharma, 2002). Among these methods, the adsorption has been found to be superior to other techniques because of its capability of adsorbing a broad range of different types of adsorbates efficiently. In recent year, there is an increase interest in using non-chemical and low-cost adsorbent (Salim et al., 2007) to remove heavy metals from wastewater.

The objective of this study was to fabricate and evaluate the feasibility of using this composite material prepared from the mussel shell and natural clay for the removal of cadmium from aqueous solution. The present research also describes the batch adsorption characteristic of $\mathrm{Cd}$ ions on the fabricated adsorbent. Experimental data have been analyzed by adsorption isotherms.

\section{MATERIALS AND METHODS}

Raw material: The natural white clay utilized for this study was obtained from Ranong province, Thailand. The clay was ground, sieved by 45-60 mesh.

The mussel shells were obtained from Samut Prakarn province, Thailand having major ingredients $\mathrm{CaCO}_{3}$. The shells obtained were dried, ground and sieved by $45-60$ mesh. Then, the fine powder was heated at $850^{\circ} \mathrm{C}$ for $4 \mathrm{~h}$.

The experimental $\mathrm{Cd}(\mathrm{II})$ solution were diluted from the standard solution $(1,000 \mathrm{ppm} \mathrm{Cd})$ with deionized water to obtain desired concentration.

Corresponding Author: Singto Sakulkhaemaruethai, Department of Chemistry, Faculty of Science and Technology, Rajamangala University of Technology Thanyaburi, Klong 6, Thanyaburi Pathumthani Thailand 12110 
Sample preparation: The adsorbent was prepared with mussel shells powder and natural clay. The mass ratio of mussel shell to natural clay was controlled as $1: 3$. The blended powder was dried at $100^{\circ} \mathrm{C}$ for $4 \mathrm{~h}$ before being used.

The surface area and its porous properties were characterized by $\mathrm{N}_{2}$ adsorption apparatus using single point Brunauer, Emmette and Teller (BET) (Autosorb1, Quantachrome, USA) procedure. The surface structure of fabricated composite material was performed by Scanning Electron Microscope (SEM JEOL, JSM-6301F, Japan).

Determining the amount of metal removal: For batch kinetic studies, $20 \mathrm{~g}$ of the mussel shells/clay beads were introduced into a $180 \mathrm{~m} \mathrm{~L}$ solution of the $\mathrm{Cd}$ (II) solution of initial concentration of $5 \mathrm{ppm}$. The samples were shaken in a thermostatic shaker at a speed of $150 \mathrm{rpm}$ at $30^{\circ} \mathrm{C}$. After a predetermined time, each solution was filtered through Whatman filter paper. The metal concentration in supernatant was determined by using an atomic absorption spectrometer (AAS, Perkin Elmer, A Analyst 800, USA).

The amount of adsorbed $\mathrm{Cd}$ ions (mg metal ions/g sorbent) was calculated using Eq. 1 from the decrease in the concentration of metal ions in the medium by considering the adsorption volume and used amount of the sorbent. The Removal efficiency $\left(\mathrm{R}_{\mathrm{e}}\right)$, determined as the $\mathrm{Cd}$ removal percentage relative to initial concentration, calculated using Eq. 2:

$$
\begin{aligned}
& \mathrm{q}_{\mathrm{e}}=\frac{\left(\mathrm{C}_{\mathrm{o}}-\mathrm{C}_{\mathrm{e}}\right) \mathrm{V}}{\mathrm{W}} \\
& \mathrm{R}_{\mathrm{e}}=\frac{\left(\mathrm{C}_{\mathrm{o}}-\mathrm{C}_{\mathrm{e}}\right)}{\mathrm{C}_{\mathrm{o}}} \times 100
\end{aligned}
$$

Where:

$\mathrm{q}_{\mathrm{e}}=$ The amount of metal ions adsorbed into unit mass of the sorbent $\left(\mathrm{mg} \mathrm{g}^{-1}\right)$ at equilibrium

$\mathrm{C}_{\mathrm{o}}=$ The initial concentration of the metal ions (ppm)

$\mathrm{C}_{\mathrm{e}}=$ The equilibrium concentration of the ions metal ions (ppm)

$\mathrm{V}=$ The volume of the metal aqueous solution $(\mathrm{mL})$

$\mathrm{W}=$ The weight of the sorbent $(\mathrm{g})$

\section{RESULTS}

Results: Figure 1 shows the SEM photograph of the prepared adsorbent (mussel shells: Clay $=1: 3$ by weight). The results revealed that the mussel shell powders have $250-355 \mu \mathrm{m}$ in size and the natural clay have a cylindrical in shape.

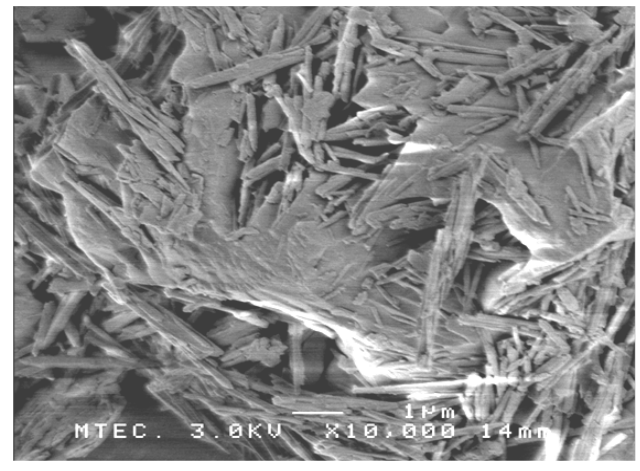

Fig. 1: SEM photograph of the mussel shell and natural clay powder

To evaluate the sorption characteristics of composite materials for $\mathrm{Cd}(\mathrm{II})$ ions, the change of sorption capacity with time for different initial concentrations has been investigated. A series of experiments were undertaken by varying the initial concentration (5 and $20 \mathrm{ppm} \mathrm{Cd(II)} \mathrm{concentrations)} \mathrm{on}$ removal kinetics of $\mathrm{Cd}$ (II) from the solution. Figure 2 showed that the residual $\mathrm{Cd}(\mathrm{II})$ ion concentration reached equilibrium in duration of $240 \mathrm{~min}$.

Kinetics of adsorption: In this study, the first-order kinetic model, which was used to examine the controlling mechanism of adsorption processes, is given as (Chiou and Li, 2003):

$\log \left(\mathrm{q}_{\mathrm{e}}-\mathrm{q}_{\mathrm{t}}\right)=\log \mathrm{q}_{\mathrm{e}}-\frac{\mathrm{k}_{1}}{2.303} \mathrm{t}$

Where:

$\mathrm{q}_{\mathrm{e}}$ and $\mathrm{q}_{\mathrm{t}}=$ The amount of $\mathrm{Cd}(\mathrm{II})$ adsorbed on adsorbent $\left(\mathrm{mg} \mathrm{g}^{-1}\right)$ at equilibrium and at time $t$, respectively

$\mathrm{k}_{1}=$ The rate constant for first-order adsorption $\left(\mathrm{L} \min ^{-1}\right)$

The straight-line plots of $\log \left(\mathrm{q}_{\mathrm{e}}-\mathrm{q}_{\mathrm{t}}\right)$ against $\mathrm{t}$ (Fig. 3) were used to determine the rate constant, $\mathrm{k}_{1}$. The $\mathrm{k}_{1}$ value and correlation coefficient $R$ given in Table 1 . The second-order equation may be expressed as (Wu et al., 2000):

$\frac{\mathrm{t}}{\mathrm{q}_{\mathrm{t}}}=\frac{1}{\mathrm{k}_{2} \mathrm{q}_{\mathrm{e}}^{2}}+\frac{\mathrm{t}}{\mathrm{q}_{\mathrm{e}}}$

where, $k_{2}$ is the rate constant for second-order adsorption $\left(\mathrm{g} \mathrm{mg}^{-1} \mathrm{~min}^{-1}\right)$. The kinetic plot between $\mathrm{t} / \mathrm{q}_{\mathrm{t}}$ versus $t$ was plotted as shown in Fig. 4. Slope and intercept values were solved to give the value of second-order rate constant given in Table 1. 
Table 1: Kinetic parameter for $\mathrm{Cd}(\mathrm{II})$ adsorption on mussel shell/natural clay beads $\left(\mathrm{C}_{\mathrm{o}}=5 \mathrm{ppm}\right)$

\section{First order}

$\mathrm{k}_{1}\left(\times 10^{-2} \mathrm{~min}^{-1}\right)$

1.3500

$\mathrm{R}$

Second order

$\mathrm{k}_{2}\left(\times 10^{-5} \mathrm{~g} \cdot \mathrm{mg}^{-1} \cdot \mathrm{min}^{-1}\right)$

$\underline{\mathrm{R}}$

0.9767

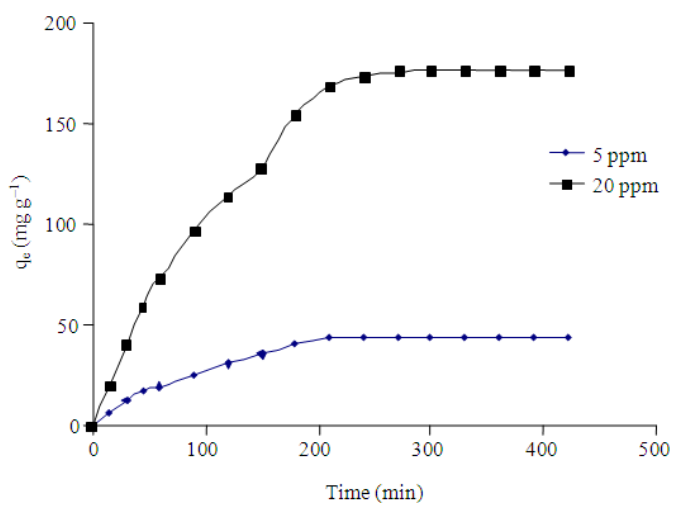

Fig. 2: Effect of initial concentration of $\mathrm{Cd}(\mathrm{II})$ adsorption by the sea mussel shell and natural clay adsorbent

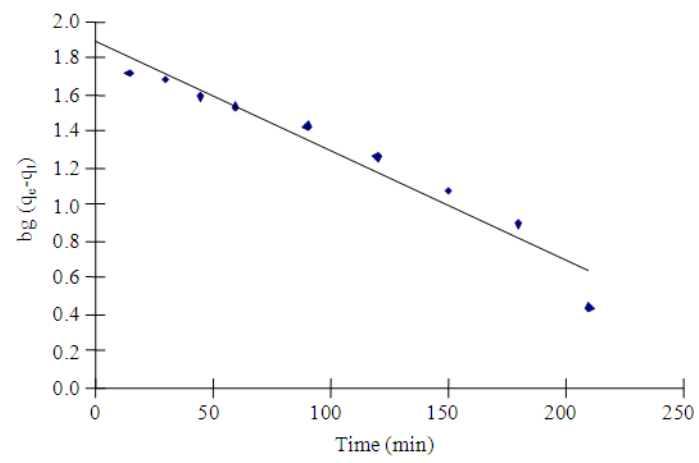

Fig. 3: Plots for first-order for $\mathrm{Cd}(\mathrm{II})$ adsorption onto the mussel shell and natural clay beads

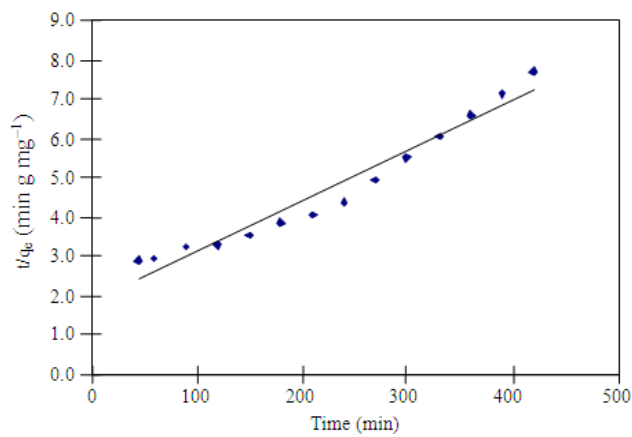

Fig. 4: Plots for second-order for Cd(II) adsorption onto the sea mussel shell and natural clay beads

\section{DISCUSSION}

As illustrated in Fig. 2, initially the amount of $\mathrm{Cd}(\mathrm{II})$ ions adsorbed increase rapidly, but then the process slows down and subsequently attains a constant value after $240 \mathrm{~min}$ i.e., when adsorption equilibrium is established. This phenomenon was due to a large number of vacant surface site for metal ions adsorption during the initial stage. Near the equilibrium the remaining vacant surface sites were difficult to be occupied due to repulsive forces between the solute molecules on the solid and bulk phase. The adsorption of $\mathrm{Cd}(\mathrm{II})$ by composite materials increases as the initial $\mathrm{Cd}$ (II) concentration increased. An increase in the initial $\mathrm{Cd}$ (II) concentration leads to an increase in adsorption capacity of the $\mathrm{Cd}(\mathrm{II})$ onto the adsorbent. This is due to the increase in the concentration gradient between the bulk and the surface of the prepared adsorbent with the increase in initial $\mathrm{Cd}$ (II) concentration. Base on the correlation coefficients, the adsorption of $\mathrm{Cd}$ (II) is best described by the second-order equation. In many cases the firstorder equation does not fit well to the whole range of contact time and is generally applicably over the initial stage of the adsorption processes.

\section{CONCLUSION}

The capability of the use of sea mussel shell and natural clay for removing $\mathrm{Cd}(\mathrm{II})$ from aqueous solution was examined. The present investigation showed that the mussel shell and natural clay beads can be effectively used as a sorbent for the removal of $\mathrm{Cd}(\mathrm{II})$ from aqueous solution. The adsorption kinetics of $\mathrm{Cd}(\mathrm{II})$ on sorbent was found to follow the second-order kinetic model.

\section{ACKNOWLEDGEMENT}

This study was financially supported by the Thailand Research Fund (TRF). The researchers wish to thank the staff from Department of Chemistry, Faculty of Science and Technology, Rajamangala University of Technology Thanyaburi.

\section{REFERENCES}

Aravindan, V., P. Vickraman and K. Krishnaraj, 2009. $\mathrm{Li}^{+}$ion conduction in $\mathrm{TiO}_{2}$ filled polyvinylidenefluoride-co-hexafluoropropylene based novel nanocomposite polymer electrolyte membrane with LiDFOB. Curr. Appli. Phys., 9: 1474-1479. DOI: 10.1016/J.CAP.2009.04.001 
Chiou, M.S. and H.Y. Li, 2003. Adsorption behavior of reactive dye in aqueous solution on chemical cross-linked chitosan beads. Chemosphere, 50: $1095-1105$. DOI: $10.1016 / \mathrm{S} 0045-$ 6535(02)00636-7

Gupta, V.K. and S. Sharma, 2002. Removal of cadmium and zinc from aqueous solution using red mud. Environ. Sci. Technol., 36: 3612-3617. DOI: 10.1021/es020010v

Inglezakis, V.J., M.A. Stylianou and D. Gkantzou, 2007. Removal of $\mathrm{Pb}$ (II) from aqueous solution by using clinoptilolite and bentonite as adsorbents. Desalination, 210: 248-256. DOI: 10.1016/J.DESAL.2006.05.049

Matlock, M.M., B.S. Howerton and D.A. Atwood, 2001. Irreversible precipitation of mercury and lead. J. Hazard Mater., 84: 72-83. DOI: 10.1016/S0304-3894(01)00190-X
Salim, M., Y. Munekage and K.M. Naing, 2007. Arsenic removal from contaminated water using silica ceramic: A batch adsorption study. J. Applied $\quad$ Sci., $\quad 7$ : 2314-2320. http://scialert.net/qredirect.php?doi=jas.2007.2314 .2320\&linkid $=$ pdf

Wu, F.C., R.L. Tseng and R.S. Juang, 2000. Comparative adsorption of metal and dye on flakeand bead-types of chitosans prepared from fishery wastes. J. Hazard Mater., 73: 63-75. DOI: 10.1016/S0304-3894(99)00168-5 